\title{
Més enllà del «mite de la secularització»: efervescència espiritual, identitats religioses i experiències transcendents
}

\section{Mar Griera}

Equip de recerca ISOR. Universitat Autònoma de Barcelona mariadelmar.griera@uab.cat

\section{Resum}

L'article pren com a punt de partida el text de Joan Estruch publicat en aquesta mateixa revista l'any 1981, on el sociòleg advertia sobre la necessitat d'abandonar el paradigma de la secularització. En aquesta mateixa línia, el present article té la finalitat d'examinar críticament les transformacions més rellevants que s'han produït en matèria de religió en els darrers trenta anys i aprofundir en les causes i les conseqüències d'aquests canvis. L'article és fruit del diàleg i l'intercanvi entre el treball de camp realitzat en el marc de diversos projectes de recerca empírics fets a Catalunya i les aportacions teòriques de la comunitat - cada vegada més nombrosa- de científics socials que investiguen sobre qüestions relacionades amb la religió.

Paraules clau: secularització; diversitat religiosa; minories religioses; experiència religiosa; transcendència; islam; cristianisme; pentecostalisme; identitat religiosa.

Abstract. Beyond the "secularization myth»: spiritual effervescence, religious identities and transcendent experiences

The article takes as its starting point the text of Joan Estruch published in this same journal in 1981, where the sociologist warned about the need to abandon the paradigm of secularization. In the same vein, this article aims to examine critically the most significant changes that have occurred regarding religion in the last thirty years and delve into the causes and consequences of these changes. The article is the result of dialogue and exchange between fieldwork carried out within the framework of several empirical research projects done in Catalonia and theoretical contributions of growing community of social scientists who investigate questions related with religion.

Keywords: secularization; religious experience; transcendency; religious diversty; religious minorities; christianity; pentecostalism; religious identity. 


\section{Sumari \\ Introducció La religió en transformació: \\ Del «mite de la secularització» pistes per desxifrar els canvis \\ a la «revenja de Déu» Apunts finals \\ A la recerca d'explicacions per un "paradigma fallit» \\ Referències bibliogràfiques}

\section{Introducció}

Son tiempos teológicos, Carvalho, cualquier afirmación sobre el futuro es teológica, porque nadie lo ha diseñado y el neodeterminismo capitalista se ha cargado la esperanza, es decir, el futuro como religión, tal como lo proponía Bloch. Por eso el gran mercado del próximo siglo será el religioso.

Manuel Vázquez Montalbán. El hombre de mi vida

Era l'any 1981 quan Enrahonar va publicar un número monogràfic al voltant de la religió. La revista va gaudir de la col-laboració del professor Joan Estruch, qui, des d'una perspectiva sociològica, va reflexionar al voltant del fenomen de la secularització amb un article titulat «El mite de la secularització». En aquell article, Estruch advertia sobre la necessitat d'abandonar el paradigma de la secularització i construir una nova mirada sobre el fet religiós. Han passat més de trenta anys des de llavors i avui torna a ser pertinent interrogar-se sociològicament sobre les transformacions en el camp religiós i examinar críticament les aportacions científiques en aquest terreny.

Deixeu-nos fer palès, d'entrada, que les reflexions que féu Estruch en aquell moment continuen tenint plena vigència $-\mathrm{o}$ fins i tot en tenen més- en el context actual. Rellegir avui el seu text fa evident el caràcter pioner $\mathrm{i}$ innovador dels seus arguments. L'objectiu d'aquest article no és, per tant, revisar críticament les aportacions d'Estruch, sinó agafar-les com a punt de partida per dibuixar i comprendre com s'ha reconfigurat la mirada sobre el fet religiós en els darrers trenta anys. Partim de la constatació que, tal com ja ens alertava Estruch, el que fou el paradigma hegemònic de la sociologia de la religió - la teoria de la secularització- ha esdevingut un «mite» poc capaç de donar compte de les característiques i les transformacions en el camp religiós. Existeix, però, una diferència clau entre el context actual i el context en el qual escrivia Estruch: avui dia, l'asseveració que la religiositat no desapareix i que la secularització és un «mite» ja no és solament una intuïció sociològica minoritària, sinó també un diagnòstic compartit. Els esdeveniments que s'han produït en matèria de religió en les darreres dècades han confirmat la intuïció d'Estruch i han contribuït a qüestionar de soca-rel les assumpcions existents darrere la teoria de la secularització. 
La finalitat d'aquest article és examinar críticament les transformacions més rellevants que s'han produït en matèria de religió en els darrers trenta anys, fixant l'atenció, especialment, a comprendre el paper d'aquestes transformacions a l'hora de provocar una nova mirada sobre el fet religiós i en la creació d'explicacions ad hoc per comprendre la incapacitat del paradigma de la secularització de preveure l'evolució de la religiositat al llarg del segle xx. L'article és fruit del diàleg i l'intercanvi entre el treball de camp realitzat en el marc de diversos projectes de recerca empírics fets a Catalunya i les aportacions teòriques de la comunitat — cada vegada més nombrosa- de científics socials que investiguen sobre qüestions relacionades amb la religió.

L'article s'estructura en tres grans parts. El propòsit de la primera part és examinar críticament el desmoronament del paradigma de la secularització a través de l'anàlisi d'un conjunt d'esdeveniments que han tingut un paper important a qüestionar-ne críticament les premisses. D'aquesta manera, utilitzem l'anàlisi dels casos particulars per resseguir críticament les debilitats de la teoria de la secularització i advertir les característiques més rellevants de les transformacions religioses. La segona part de l'article desgrana les raons que, des de les ciències socials, s'han proposat per explicar per què les prediccions de la teoria de la secularització no s'han fet realitat. A la tercera part, hi exposem dos dels canvis que considerem més rellevants - i significatius - de la transformació de l'escenari religiós. L'article es conclou amb uns breus apunts finals.

\section{Del «mite de la secularització» a la «revenja de Déu»}

Fins a finals de la dècada de 1980, la teoria de la secularització gaudí d'un estatus hegemònic en el marc de la sociologia de la religió (Casanova, 1994). L'article d'Estruch, publicat l'any 1981, fou precursor d'un seguit d'aportacions que posaren en qüestió les tesis, l'abast i les implicacions de la teoria de la secularització i n'erosionaren el caràcter paradigmàtic.

En aquell text, Estruch hi desafiava el «sentit comú acadèmic», que, ancorat en la creença de la incompatibilitat radical entre modernització i religió, pronosticava un futur sense déus. En aquest sentit, afirmava:

[...] el que s'amaga darrera totes les teories de la secularització, tant en la seva vessant sociològica com en les seves variants teleològiques, és una incapacitat bastant radical de superar l'estadi de les profecies decimonòniques sobre la decadència i futura desaparició de la religió. (Estruch, 1981: 45)

Des de Voltaire, la raó s'havia erigit com l'antídot vers el regne de «tot allò irracional», i el procés d'extinció de la religió era considerat quelcom inevitable $\mathrm{i}$ irreversible. El teòleg anglicà Thomas Woolston va ser un dels primers que es va atrevir a fer prediccions sobre la fi de la religió. L'any 1700 pronosticà que la religió desapareixeria el 1900 . Woolston pensava que l'avenç de la ciència, la tècnica i el pensament racional convertiria la fe religiosa en un vestigi del passat. No fou l'únic a esgrimir aquests arguments. El mateix Voltaire, en 
una carta a Frederic el Gran escrita l'any 1770, afirma: «La religió no durarà més de cinquanta anys» (Stark, 1999).

Al llarg del segle xx, la disminució de la pràctica religiosa i la menor presència pública de l'Església a Europa van atorgar credibilitat a aquestes prediccions. Es considerà que l'avenç de la ciència, la industrialització de les societats, la urbanització i la millora de la qualitat de vida eren incompatibles amb la creença i la pràctica religioses. Durant dècades, els científics socials interpretaren que el creixement constant i gradual de persones que abandonaven la pertinença a les esglésies cristianes a Europa era una conseqüència directa, $\mathrm{i}$ inevitable, de la modernització del continent. Hom pensava que ser modern era incompatible amb ser religiós i, per tant, el futur de les religions a Europa es preveia curt i poc gloriós. Es considerava, a més, que, a mesura que la resta del món s'anés modernitzant, també s'aniria secularitzant, amb totes les conseqüències que això comportava: disminució de la pràctica i la creença religioses, reclusió de la religió a l'esfera privada, pèrdua d'influència i de significació dels moviments religiosos i creixement de l'ateisme, entre d'altres qüestions.

$\mathrm{Al}$ tombant de segle, el diagnòstic sobre la situació de la religió ha canviat. El debat sobre el futur de la religió s'ha fet més complex i són nombrosos els científics socials que fan palesa la necessitat d'anar més enllà del que és aparent a simple vista. Així, si bé és innegable que la religió viu moments de canvi en la nostra societat i que les esglésies tradicionals perden fidels, és menys evident que aquestes transformacions impliquin una desaparició total i completa de la religiositat. En aquesta línia, i com ens recorda Joan Estruch, és convenient no oblidar-se de Durkheim quan deia: «No hi ha cap evangeli que sigui immortal, però no hi ha cap raó per creure que la humanitat no pot crear-ne de nous», o de Mircea Eliade, quan ens alertava que "parlar d'una societat irreligiosa només denota una incapacitat per desvelar el que és sagrat».

El punt d'inflexió en el descrèdit acadèmic del paradigma de la secularització el constitueix la publicació del llibre de Peter Berger The desecularization of the world (1999), en el qual, l'autor —un dels sociòlegs de la religió amb més prestigi internacional i reconegut defensor de la teoria de la secularització- es retracta de bona part de les seves aportacions anteriors. Berger (1999: 2) escriu: «Actualment, el món [...] és tan ferotgement religiós com sempre ho ha estat $\mathrm{i}$ en determinats indrets és, fins i tot, més religiós que mai». El sociòleg nord-americà acusa els acadèmics - $\mathrm{i}$ a tots els que ell agrupa sota l'epígraf d' "elits seculars", com ara periodistes, intel-lectuals, polítics i professionals del món de la cultura- d'haver estat incapaços de veure què passava més enllà dels cercles intel.lectuals i d'haver restat absolutament miops davant el creixement de la religiositat. En aquest procés de desprestigi de les tesis de la secularització, també hi tenen un paper cabdal obres com ara Public religions in the modern world (1994), de José Casanova, on l'autor qüestiona la tesi de la privatització de la religió, o el llibre Formations of the Secular: Christianity, Islam, Modernity, de Talal Assad (2003), on l'antropòleg revisa les bases ideològiques, polítiques i culturals del paradigma de la secularització. Altres autors, com ara la sociòloga britànica Grace Davie, la francesa Hervieu-Léger o el 
mateix Joan Estruch, entre molts altres, han contribuït també a posar en qüestió la que fou una de les teories amb més credibilitat dins les ciències socials a mitjan segle $\mathrm{xx}$.

La crítica acadèmica a la teoria de la secularització es produeix en paral.lel a l'emergència i el sorgiment d'un seguit de fenòmens a nivell mundial que esdevenen «envits» —en el sentit bourderià d'enjeux — per a la sociologia de la religió. Envits que fan esclatar la reflexió i que impulsen el pensament a anar més enllà d'allò que es dóna per descomptat. És Gilles Kepel qui, afirmant el caràcter inesperat, $\mathrm{i}$ alhora crucial, d'aquests nous moviments religiosos, s'hi refereix amb l'expressió «la revenja de Déu». Són, en certa manera, esdeveniments que, en el llenguatge de Kuhn (1962), representen «anomalies» que contradiuen el paradigma i que posen en suspensió la validesa de les seves premisses.

Arreu del món, els moviments religiosos guanyen rellevància i visibilitat: des d'Israel fins a Guatemala, passant per Polònia o el Brasil i arribant fins a la Xina, Nigèria o l'Iran. Només l'Europa occidental es manté, aparentment, al marge d'aquesta revifalla (una aparença que, com veurem més endavant, també convindrà posar en quarantena). Ara bé, és arriscat englobar tots aquests moviments sota un mateix enunciat, ja que ens trobem amb un repertori molt variat de realitats difícilment comparables. En certa manera, cadascun d'aquests moviments té un tarannà i unes característiques particulars, alhora que, en funció del context històric, social i cultural on s'inscriuen, adopten rols diferents: des de refugis identitaris del que és tradicional fins a portadors de noves ideologies o espais de sociabilitat i cohesió social, entre d'altres. En la diversitat, però, podem trobar un mínim comú denominador, i és que tots, d'alguna manera o altra, desafien les categories tradicionals a través de les quals es concebia la religiositat en el marc del paradigma de la secularització.

A continuació, em referiré, breument, a sis esdeveniments ${ }^{1}$ que es produeixen a partir de les acaballes de la dècada de 1970 i que mostren la transformació de l'escenari religiós. Cadascun d'aquests esdeveniments es converteix, en certa manera, en una «anomalia» que debilita el potencial heurístic del paradigma de la secularització i que en qüestiona la validesa. La selecció dels casos no és ni exhaustiva ni excloent, sinó que està feta amb la voluntat que esdevinguin il.lustratius de les transformacions en l'escenari religiós i que, alhora, permetin fer evidents les assumpcions de la teoria de la secularització que posen en "quarantena».

Un primer esdeveniment que cal remarcar és el paper del pontificat de Joan Pau II en el marc del catolicisme. L'elecció del nou papa, Karol Wojtyła, el setembre de 1978, marca un punt d'inflexió. I és així per dues raons: primer, perquè revisa l'aggiornamento del Concili Vaticà II i frena el que semblava un camí irreversible vers la democratització i la modernització de l'Església catòlica. Ratzinger encara ha aprofundit més en aquesta via i ho ha complementat

1. Kepel fa la seva pròpia selecció dels elements que ell considera més rellevants. Jo he tingut en compte les seves observacions, però hi he afegit algunes qüestions i n'he eliminat d'altres. La perspectiva temporal més àmplia de la qual jo disposo —ell va escriure el seu llibre l'any 1994 - i la mirada sociològica — i no tan fonamentada en un contingut estrictament polític- fa que divergim lleugerament en la selecció. 
amb un cert retorn a la ritualitat, emfasitzant molt les formes de la "posada en escena» de la fe (vestimenta, gestos, llenguatge) que el Concili Vaticà havia desplaçat a segon terme. L'altra raó per la qual cal prendre l'elecció de Wojtyła com un punt d'inflexió és la construcció mediàtica que se'n fa -i que ell mateix afavoreix - com a personatge públic amb característiques properes als «ídols de masses» (les trobades amb joves i adolescents, les aparicions estel-lars a la televisió, la presència als mitjans al costat d'altres estrelles mediàtiques, etc. —Sáez, 1997). Una construcció mediàtica que cristal-litzà amb tota la força possible en la retransmissió de la seva malaltia, que es va dur a terme els dies abans de morir. La mort de Joan Pau II i el tractament públic i mediàtic que se'n va fer són el millor retrat de les innovacions que el seu pontificat va introduir. Unes altres accions, com ara el creixement de determinats moviments d'església — per exemple: el Camí Neocatecumenal o Comunió i Alliberament, entre d'altres - o les noves campanyes d'evangelització, són també il.lustratives del nou rumb emprès per l'Església catòlica. És significatiu tenir-ho en compte, perquè, en certa manera, a partir de l'elecció del papa Wojtyła, l'Església s'allunya d'un cert procés de «racionalització» de la fe atenent criteris «moderns» que havia promogut el Concili Vaticà II i que, en certa manera, aproximava el catolicisme a l'ethos il.lustrat (i secular).

En aquest escenari, hi ha un segon esdeveniment que esdevé crucial i que ha derivat en conseqüències inimaginables arreu del món. Ens referim a la revolució de l'Iran que va tenir lloc l'any 1979. Fou un fenomen que agafa desprevinguda la majoria de politòlegs i experts en relacions internacionals (Thomas, 2005). La revolució s'inicia amb el retorn, el mes de febrer de 1979, de l'aiatol-là Khomeyni a Teheran i immediatament després es proclama la República Islàmica. En certa manera, a més, a la dècada dels anys setanta, els moviments islàmics s'estenen des de Malàisia fins al Senegal, des de les repúbliques soviètiques fins a les grans metròpolis europees. Es propicia el denominat «ressorgiment de l'islam» i la "reislamització des de baix». El propòsit és, segons aquests autors, reislamitzar la vida quotidiana i els costums i trencar la lògica de la modernitat secular percebuda com a còmplice de la corrupció generalitzada i les desigualtats socials (Kepel, 1994; Huete, 2007). En bona mesura, la comunitat imaginada de l'umma islàmica pren força com a vehicle de mobilització i de cohesió enfront del «secularisme» europeu (Thomas, 2005).

Referint-se a aquests dos esdeveniments, Kepel (1994: 2) afirma: «Al voltant de 1970 [...] un nou enfocament religiós va començar a prendre forma [...]: el tema ja no era l'aggiomamento, sinó la «segona evangelització d'Europa», i l'objectiu ja no era modernitzar l'islam, sinó islamitzar la modernitat».

L'arribada de Ronald Reagan a la presidència dels EUA l'any 1980 és, també, un esdeveniment crucial que Kepel destaca. I ho és per una raó molt senzilla: la seva candidatura va tenir el suport explícit de la coalició Majoria Moral formada recentment i, segons van destacar els analistes, el suport d'aquesta coalició fou la clau de volta que li permeté guanyar els comicis. L'emergència de Majoria Moral en el panorama sociopolític nord-americà agafa per sorpresa moltes de les «elits seculars» (Berger, 1999) i va posar sobre la taula 
que la línia divisòria fonamental de la política nord-americana es dibuixava entorn de les qüestions amb una forta connotació religiosa (l'avortament, el matrimoni homosexual, etc.). A més, va fer evident el creixement soterrat dels nous moviments evangèlics - de tall fonamentalista- que, fins aleshores, havien passat desapercebuts als ulls de la majoria ${ }^{2}$. El creixement de Majoria Moral i la reivindicació explícita de la seva voluntat de no desvincular les raons polítiques (o públiques) de les raons religioses desafia el que havia estat, fins aleshores, la tònica dominant o la font de legitimació de la democràcia concebuda com un sistema laic amb una separació entre la moral de l'esfera pública (i, per tant, l'argumentari «legítim» a l'esfera pública) i la de l'esfera privada. Aquest fet, en certa manera, no és exclusiu del cas nord-americà, ans, com emfatitza Thomas (2005: 26):

La revifalla global de la religió posa en relleu els vincles entre la religió i la política arreu del món. I, especialment, posa fortament en qüestió un dels principis de la mitologia política de la modernitat liberal: la idea que la religió ha de ser reclosa en l'esfera de la vida privada i mantinguda fora de l'espai de la política.

El quart esdeveniment que em sembla imprescindible destacar - i que considero un dels més rellevants, malgrat que hagi passat força desapercebutés el creixement extraordinari del pentecostalisme arreu del món i, especialment, a l'Amèrica Llatina (Martin, 1990; Bastian, 1997; Vasquez, 1999). El pentecostalisme, que neix a Los Angeles a principis del segle xx, és un corrent protestant caracteritzat pel minimalisme doctrinal, per la important dotació expressivoemocional del culte i per la seva flexibilitat organitzativa i doctrinal que el converteixen en un "producte» facilment exportable i/o adaptable a contextos molt diversos (Griera, 2013). És al voltant de la dècada de 1970 quan el creixement del pentecostalisme comença a prendre embranzida. Des dels cercles acadèmics, s'acusà el pentecostalisme de ser la rereguarda ideològica del govern nord-americà, que tenia interessos objectius per frenar el creixement de la teologia de l'alliberament al continent (Stoll, 1990). Tanmateix, però, i sense negar que, segurament, el govern nord-americà mostrà una bona disposició a promoure el pentecostalisme a l'Amèrica Llatina, reduir l'explicació del fenomen a les teories conspiratives és excessivament simplista (Cantón Delgado, 1998). I és que la importància del pentecostalisme en el context llatinoamericà actual ha augmentat molt $i$ ha sobrepassat de llarg qualsevol expectativa inicial. A més, actualment, els líders i impulsors del moviment són els propis llatinoamericans, i no pas els missioners d'origen nord-americà. Més d'un 28\% de la població de l'Amèrica Llatina manifesta que és pentecostal, segons dades de la World Christian Database (2001), mentre que aquesta xifra no arribava

2. Uns moviments que, com diu Kepel (1994: 8): «varen afectar tots els nivells de la societat. No estaven confinats al estats rurals del sud, sinó que van atreure membres tant de les minories negres i hispàniques com de la classe mitjana anglosaxona i protestant, a més, van desenvolupar unes xarxes molt potents de predicació i finançament, gràcies a l'ús estratègic de la televisió i de maneres avançades i sofisticades de difondre del seu missatge». 
al 4\% l'any 1970. És a dir, en quaranta anys, hi ha hagut gairebé un terç de la població del territori que s'ha convertit al pentecostalisme, amb totes les implicacions que això suposa. No hi ha cap més moviment religiós que mostri una taxa de creixement tan elevada en tan poc temps. És a dir, malgrat que acostumem a focalitzar l'atenció en l'islam, és el pentecostalisme qui augmenta més notablement el nombre de fidels i qui, a més, aconsegueix trencar amb el vell principi "Cuius regio, euis religio», la qual cosa fa que el pentecostalisme es converteixi en un ferm candidat a posar en dubte l'hegemonia catòlica de la regió llatinoamericana. Sense oblidar, a més, que el pentecostalisme també creix de forma rellevant a l'Àfrica — a països com ara Ghana o Nigèria—i a l'Àsia —a països com ara Filipines, Corea o la Xina (Anderson, 2004; Martin, 2002; Corten i Marshall-Fratani, 2001)—, com també entre els gitanos a casa nostra (Méndez, 2005).

L'any 1989, succeeixen dos esdeveniments que tenen conseqüències cabdals en matèria de religió: la caiguda del mur de Berlín - de la qual parlarem unes quantes ratlles més avall- $\mathrm{i}$ la publicació de l'obra Els versos satànics, de Salman Rushdie. El llibre de l'autor indobritànic va provocar una controvèrsia molt forta en el món musulmà, a causa de la suposada irreverència amb la qual es retrata el profeta Mahoma. L'obra va generar reaccions immediates: molts països van prohibir-ne la publicació (Índia, Pakistan, Sud-àfrica, Malàisia, etc.), es van fer protestes a diverses ciutats del món, l'aiatol-là Khomeyni va publicar una fatwa en què instava a executar l'escriptor, es va assassinar el traductor de l'obra al japonès, l'editor noruec va ser tirotejat i un llarg etcètera d'altercats $\mathrm{i}$ revoltes. L'anomenat «afer Rushdie» va causar una gran consternació a Europa i, com exposa la sociòloga britànica Grace Davie (2006b), es va convertir en un punt d'inflexió. I és que l'afer Rushdie va posar sobre la taula tres grans qüestions:

a) La població musulmana a Europa era cada vegada més nombrosa. No es tractava d'un grup aillat, sinó que, en bona mesura, formava una "comunitat imaginada" (Anderson, 1993) d'abast transnacional.

b) Els immigrants musulmans no se «secularitzaven» en arribar a Europa, sinó que, més aviat, articulaven la identitat i la vinculació comunitària al voltant de l'adhesió a l'islam.

c) La "gestió de l'islam» — i, en general, la gestió dels afers religiosos- és un camp complex i ple de dilemes i contradiccions (Bader, 2007; Laurence, 2006; García-Romeral, 2013).

Em sembla també imprescindible posar de relleu el creixement de l'Església ortodoxa als antics països de l'òrbita soviètica. En aquest sentit, malgrat que l'ateisme polític va ser la doctrina dominant de la Unió Soviètica, i a pesar de tots els esforços per allunyar la religió de la població, en els anys posteriors a la caiguda del mur s'ha viscut un reviscolament de les identitats religioses (Borowik, 2002). Darrere la doctrina de l'ateisme polític — i també darrere de la teoria de la secularització-, hi havia l'assumpció que la secularització era un 
fenomen irreversible: una vegada t'havies secularitzat i havies desterrat déu de la teva vida quotidiana, això esdevenia un fenomen irreversible. En certa manera, i dit amb paraules de l'època, es pensava que, una vegada que el pensament racional havia guanyat la partida, la religió ja no hi tenia res a fer. No obstant això, però, el que ha succeït en els països de l'Est en els darrers temps ha posat en relleu que la secularització no és quelcom irreversible, sinó que es pot provocar un canvi de tendència i retornar a l'escenari religiós. L'Església ortodoxa viu un moment de creixement, unit també al reforçament de les identitats nacionals i a l'articulació de nous valors de cohesió en les societats capitalistes.

Un darrer element que convé destacar és l'expansió i l'èxit internacional de noves formes d'espiritualitat que, entorn de certs «valors orientals» —o de la interpretació occidental de les religions orientals—, difonen arreu - $\mathrm{i}$, especialment, a Europa - una nova doxa sobre el subjecte i la transcendència espiritual. La fama internacional del dalai-lama i l'èxit absolut de les convocatòries que el tenen a ell com a convidat són una mostra del creixement semisoterrat d'aquesta nova mena d'espiritualitat líquida arreu del món occidental. La cartografia d'aquesta espiritualitat mostra un mapa molt complex i ple de matisos (Heelas i Woodhead, 2005; Fedele, 2009; Illouz, 2008), però, a manera de resum, podem afirmar que és un tipus d'espiritualitat que es vehicula a través del consum de «pràctiques» espirituals i de la vivència d'experiències puntuals d'efervescència - moments que es vertebren entorn de la visita del dalai-lama, de l'amma o d'altres líders espirituals, com també al voltant de l'organització de rituals diversos, com pot ser el solstici d'estiu o un festival de ioga. Una forma d'espiritualitat que difon els seus principis a través dels llibres d'autoajuda i que promou un seguit de creences - la reencarnació, l'energia, la concepció holística de l'ésser, la vinculació entre cos i ment, entre d'altres - que, cada vegada més, esdevenen incorporades al «sentit comú» hegemònic (Houtman i Aupers, 2007; Griera i Urgell, 2002). El creixement d'aquest nou tipus d'espiritualitat, a més, ens mostra que la religió pot desenvolupar-se més enllà dels confins de les institucions religioses. Es produeix, així, una desinstitucionalització i, alhora, una desregulació dels símbols religiosos que els fa "accessibles» a través del mercat i la cultura pop, i els allunya de les institucions religioses tradicionals.

Tots aquests esdeveniments contribueixen a qüestionar el «mite de la secularització», esdevenen anomalies que erosionen la credibilitat del paradigma i que en posen en dubte la capacitat explicativa. Són esdeveniments, també, que ens mostren la fragilitat d'algunes de les premisses existents rere la teoria; premisses com ara la irreversibilitat del procés de secularització que pressuposa, a més, una concepció lineal de l'evolució; la necessitat de mantenir la religió en l'esfera privada, o la inevitabilitat de la disminució de la creença en les societats dites «modernes». Alhora, tots aquests moviments desafien les assumpcions implícites en la manera de pensar la religió. Ens mostren, així, que la teoria de la secularització anà molt unida a una concepció «clerical» — i/o institucionalde la religiositat, i ens fan evident que predomina una concepció de religiositat mesurada a través d'uns indicadors amb un fort biaix «cristià» (Estradé, 2003). En aquest sentit, Casanova (2007: 7) afirma: 
La categoria de secularització difícilment es pot aplicar, per exemple, a religions com ara el confucianisme o el taoisme. I és que aquestes religions no es caracteritzen per mantenir una relació de tensió amb el que és mundà. El seu model de transcendència difícilment pot ser dit «religiós» $\mathrm{i}$, a part, no disposen d'una organització eclesiàstica. [...] Secularitzar, que vol dir 'fer profa' o 'transferir de l'ús eclesiàstic al civil' —és un procés que no té gaire sentit en aquesta civilització.

\section{A la recerca d'explicacions per un "paradigma fallit»}

A començaments del segle XXI, el consens entorn de la necessitat de revisar o abandonar el paradigma de la secularització és, gairebé, hegemònic. Són diversos els científics socials que han cercat explicacions per tal de poder detectar els elements erronis de la teoria de la secularització amb l'objectiu de comprendre les causes - i les conseqüències - dels canvis en matèria de religió. Les aportacions són nombroses i resseguir-les totes seria impossible. Ens concentrarem en les tres que han tingut més ressò.

En primer lloc, un conjunt de sociòlegs nord-americans ${ }^{3}$, aplegats a l'entorn de la revista Journal for the Scientific Study of Religion, promouen la coneguda teoria del «mercat religiós». La seva proposta neix com a resposta a la perplexitat que els provoca adonar-se que, malgrat les prediccions de la teoria de la secularització, als Estats Units la modernitat no implicava una davallada de les creences ni de les pràctiques religioses. És més, estudis realitzats per Rodney Stark i Roger Finke sobre l'evolució de la pertinença religiosa als EUA durant dos segles mostren que, l'any 1776 , només un $17 \%$ de la població participava en una església, mentre que l'any 2000 aquest percentatge era del 62\% (Stark i Finke, 2000: 23). És a dir, paradoxalment, es produeix un creixement i no pas un descens de la religiositat. Amb la voluntat d'explicar aquestes qüestions, sorgeix la teoria del "mercat religiós», que, a redós de la teoria de l'elecció racional i la lògica economicista, aposta per canviar de perspectiva en l'anàlisi de les transformacions de la religió. Des del seu punt de vista, l'error principal de la teoria de la secularització és que ha pres com a variable clau els canvis en la «demanda» i no s'ha adonat que l'aspecte fonamental per entendre com funciona el «mercat religiós» és tenir en compte l'oferta. Segons aquests autors, la demanda és estable - la necessitat de "religió" té arrels bioantropològiques-, però l'oferta, en canvi, és variable. Per aquest motiu, la manera que té el mercat religiós de funcionar — i la regulació d'aquest- representa un paper molt important per entendre les transformacions en matèria de religió. És, en certa manera, la doxa neoliberal aplicada a la religió. Segons aquests autors, un alt nivell de regulació i de control del mercat per part de l'estat desincentivarà les organitzacions religioses i potenciarà la creació d'un mercat ineficient des del punt de vista de les teories econòmiques. És a dir, l'oferta religiosa no es

3. Entre els quals podem mencionar Roger Finke, Rodney Stark, Lawrence R. Iannaccone, William Sims Bainbridge i R. Stephen Warner. 
podrà desenvolupar i, per tant, la participació de la població en afers espirituals serà menor, al mateix temps que el fet que no existeixi prou competència provocarà que el producte no «millori» — i aquest és el cas de la majoria de països europeus, ens diran. Així, la teoria del mercat religiós explica, segons els seus autors, les diferències entre Europa i els Estats Units. Europa és una societat on l'estat ha tingut un paper preponderant com a regulador del mercat religiós, la qual cosa ha impossibilitat que sigui «veritable» $\mathrm{i}$ «lliure». La majoria de països europeus ha viscut situacions de monopoli o d'oligopoli religiós, per aquest motiu, avui trobem tan poca «competència» religiosa. En relació amb el paradigma de la secularització, aquests autors es posicionen afirmant que allò que caracteritza les societats europees no és la secularització, sinó la dessacralització de la societat, i que els teòrics de la secularització han confós els dos conceptes. En aquest sentit, segons Stark i Iannaccone la sacralització es produeix quan una organització religiosa aconsegueix ostentar una posició de monopoli i exercir una influencia en tot el funcionament de la societat i en totes les esferes socials. Actualment, però, les societats europees estan vivint un procés de dessacralització que provoca una disminució de la capacitat d'influència de les esglésies monopolistes vers la societat i els individus. No es pot confondre, però, la secularització amb la dessacralització. En aquest sentit, Stark i Iannaccone (1994: 235) afirmen:

A curt termini, la dessacralització pot donar l'aparença de secularització. Cal destacar, però, que aquest tipus de "secularització» és temporal i limitada en gran part a la disminució de la participació religiosa — mai és equivalent a l'«extinció» de la religió proposada per les teories estàndard de la secularització.

Aquesta proposta té defensors acèrrims i, també, nombrosos detractors. No hi entrarem en detall, ans són conegudes les crítiques a l'aplicació de la teoria de l'elecció racional per comprendre l'acció social (Muntanyola, 2013; Bruce, 1993). Unes crítiques que, a més, reben el meu suport i que comparteixo plenament. Ara bé, reconeixem, també, la utilitat d'aquest enfocament que ens proporciona una nova mirada sobre el fet religiós - la qual cosa situa l'oferta religiosa al punt de mira.

En segon lloc, és Peter Berger qui ens ofereix una altra lectura sobre les raons que s'amaguen rere el fracàs de les prediccions de la teoria de la secularització. El sociòleg nord-americà argumenta que allà on erraren la majoria de sociòlegs —àdhuc ell mateix en les seves primeres anàlisis- és en la menysvaloració del paper del pluralisme i en la sobrevaloració del rol de la secularització en l'emergència i el desenvolupament de les societats modernes. Des del punt de vista de Peter Berger, el que caracteritza la modernitat és el pluralisme i no pas la secularització. El pluralisme, ens dirà Berger, és consubstancial a la modernitat, però la secularització no. Moltes vegades, la modernització ha anat acompanyada d'un procés secularitzador, però això no sempre ha estat així $\mathrm{i}$ tampoc ha de ser, forçosament, així. En determinats casos, el pluralisme pot conduir a la secularització, però, en d'altres, també pot esdevenir un terreny fertil per a la vigorització religiosa. En certa manera, la modernitat i els pro- 
cessos que s'hi associen — com ara el creixement de les migracions, la importància de les noves tecnologies de la informació, l'emergència de circuits globals de relació o la urbanització, entre d'altres - han afavorit el creixement del pluralisme, tant si és entès en termes confessionals - d'organitzacions religioses_- com en termes més genèrics — com a opcions de vida. I aquest creixement del pluralisme té, com apunta Peter Berger (2005: 10), unes conseqüències determinades. En aquest sentit:

[...] històricament, la religió era una part essencial d'allò que es donava per descomptat. La psicologia social ens ofereix una idea clara de com el que es dóna per descomptat es manté a la consciència: és el resultat del consens social en l'entorn de l'individu. I, durant gran part de la història, la vida de la major part dels individus tenia lloc en entorns d'aquesta índole. El pluralisme debilita aquest tipus d'homogeneïtat. L'individu es veu contínuament enfrontat a unes altres persones, que no donen per fet allò que tradicionalment es donava per descomptat en la seva comunitat. Ara ha de reflexionar sobre els supòsits cognitius i normatius de la seva tradició i, en conseqüència, ha d'escollir. Una religió que s'escull, en qualsevol nivell de complexitat intel-lectual, és diferent d'una religió que es dóna per descomptada.

En la modernitat, la creença es transforma en una opció subjectiva realitzada a partir d'una tria, d'una elecció, i aquest fet la converteix, inevitablement, en més fràgil i vulnerable, alhora que la fa més propensa a patir un cert «fonamentalisme». És en aquest punt on Berger insisteix en la necessitat de tenir en compte que la revitalització religiosa actual en cap cas ha de ser llegida com una recrudescència d'una religió arcaica, tradicional, que perviu en temps que no són els seus, sinó, més aviat, com una conseqüència de la modernitat $i$, per tant, una resposta a aquesta mateixa modernitat. En aquesta línia, Berger afirma: «Hi ha una diferència crucial entre la religió tradicional i la neotradicional. Psicològicament, la primera pot ser molt relaxada i tolerant, la segona és necessàriament tensa i té una certa inclinació cap a la intolerància» (Berger, 2005: 11). En el món modern, la certesa religiosa és molt difícil d'assolir i el creient es veu obligat a negociar entre el relativisme i el fonamentalisme, la qual cosa atorga a l'experiència psicocognitiva de la creença un caràcter qualitativament diferent del que tenia en una societat tradicional. Això és el que Berger defineix com l'imperatiu herètic i marca el trànsit del món tradicional del destí a la societat moderna de l'elecció. El pluralisme, alhora, també té efectes a nivell de l'organització institucional de la religió: en una societat plural, les organitzacions religioses es veuen obligades a competir entre elles per aconseguir atraure fidels, i aquest fet les situa en una posició particular. Així, la «veracitat» del seu missatge pot ésser posada en dubte $i$ es veuen obligats a "vendre» $\mathrm{i}$ a convèncer de la «qualitat» del seu missatge, alhora, la seva autoritat ja no és donada per descomptat i als líders els cal «seduir» i convèncer els fidels. En definitiva, ens dirà Berger, el pluralisme és inherent a la modernitat i no en podem menystenir les conseqüències que genera, tant a nivell individual com a nivell institucional. En alguns casos, el pluralisme ha tingut com a conseqüència 
l'esmorteïment de la creença i la pràctica religioses — com és el cas de l'Europa occidental—, en d'altres, però, ha donat lloc a la puixança religiosa, com és el cas de determinats indrets de l'Amèrica Llatina o de l'Europa de l'Est, entre molts altres.

Una tercera explicació que ha pres volada en les darreres dècades, i que en cap cas és incompatible amb les anteriors, és la que focalitza la mirada en la modernitat i s'interroga sobre el seu caràcter. El sociòleg israelià Shmuel Eisenstadt cridà l'atenció sobre el fort biaix eurocèntric imprès en la mirada sobre la modernitat, i també sobre la secularització. Eisenstadt (2002) emfatitzà la necessitat de superar la idea que la modernitat és com un motlle prefabricat d'origen europeu que es va reproduint arreu del món. Ell utilitzà el concepte de «modernitats múltiples» per explicar que la modernitat és resultat de la imbricació concreta entre nombrosos factors (històrics, polítics, culturals, socials, etc.) que configuren un model específic únic i diferenciat en cada espai territorial - i, paral-lelament, que el rol que la religió pot tenir en cadascun d'aquests models pot variar notablement. És a dir, no podem considerar la secularització com una conseqüència inevitable de la modernització, sinó que la relació entre modernitat i religió és més complexa i, alhora, dependent del context particular. La sociòloga britànica Grace Davie, conjuntament amb Peter Berger i Effie Fokas (2008), apliquen aquesta perspectiva per comprendre les diferències entre els Estats Units d'Amèrica i l'Europa occidental en termes de religió i afirmen el següent: és moment de prendre consciència que Europa no és secular perquè és moderna, ni és moderna perquè és secular, sinó que, paradoxalment, és secular i moderna justament perquè és Europa. És a dir, la situació de la secularització a Europa és conseqüència de l'existència d'unes dinàmiques específiques internes i externes de la cristiandat europea occidental que, des de l'edat mitjana fins a l'actualitat, han anat dibuixant la particularitat del continent. No se'n pot inferir, però, que, a la resta del món, la tònica dominant serà similar a Europa, sinó que, en cada indret, es configurarà una relació de forces específica que contribuirà a atribuir un $\mathrm{lloc}$ - $\mathrm{O}$ un altre- a la religió.

Fins aquí, hem resseguit tres aportacions que ofereixen una explicació dels equívocs inherents a la teoria de la secularització i que ens permeten entendre la complexitat de la relació entre la modernitat i la religió. Cadascuna d'aquestes aportacions fixa la mirada en un element concret: el comportament de l'oferta —en el cas de les teories del «mercat religiós»—, les conseqüències del pluralisme - en el cas de la teoria de Berger - i el caràcter de la modernitat - en el cas de la contribució d'Eisenstadt. Les tres teories no són incompatibles, sinó que totes tres ens donen pistes per ajudar-nos a reconstruir la mirada sobre el fet religiós i a desxifrar la idiosincràsia dels canvis en matèria de religió.

\section{La religió en transformació: pistes per desxifrar els canvis}

Aquestes tres aportacions ens ajuden a comprendre per què ha fallat el paradigma de la secularització, però, en canvi, ens ofereixen poca informació sobre la naturalesa de les transformacions que s'han produït en els darrers anys 
en matèria de religió. En aquest sentit, són nombrosos els autors que insisteixen a dir-nos que és necessari deixar de focalitzar-nos en el debat sobre la secularització i centrar-nos en les múltiples alteracions que pateix l'adhesió religiosa en l'actualitat. Per exemple, Yamane (1997), partint dels nombrosos estudis etnogràfics fets a Middletown, apunta que és necessari tenir en compte que, en els darrers anys, s'ha produït un canvi qualitatiu en les maneres de creure. Per això, més enllà dels diagnòstics a gran escala en termes de secularització i pluralisme, cal documentar, explorar i radiografiar com es transforma el fet de creure a petita escala en l'exercici diari i quotidià. Fer això no és senzill i encara menys exposar-ho resumidament. Són molt nombrosos els canvis que es produeixen $i$, alhora, és molt important el context particular on es produeixen, la qual cosa converteix aquest propòsit en una tasca inabastable en el marc d'aquest article.

No obstant, però, i advertint del risc d'una simplificació excessiva, sí que és possible emfatitzar dues de les transformacions que, en vista de l'escenari actual, semblen més significatives i, alhora, més transversals. Dues transformacions que, d'una manera o altra, impregnen la majoria d'esdeveniments mencionats a la primera part d'aquest article i que imbueixen bona part dels canvis que s'estan produint en matèria de religió en l'actualitat. D'una banda, cal remarcar el protagonisme creixent que adquireix l'experiència subjectiva del transcendent en la vivència del fet de creure en l'actualitat. I, d'altra banda, la importància que prenen les religions com a vehicle d'identificació i recurs per a la construcció identitaria ${ }^{4}$. Són dos fenòmens que tenen causes i consequiències d'índole diferent i que convé analitzar de forma separada. És més, justament, el fet característic —o fins i tot paradoxal — és que les conseqüències d'una transformació poden, en certa manera, semblar contradictòries als efectes de l'altre. Ho exposarem més endavant.

En relació amb la primera transformació, i seguint, en bona part, el mestratge de Thomas Luckmann, cal ressaltar que és el sociòleg alemany Hubert Knoblauch (2008) qui ens avisa de la importància que adquireix l'experiència de la transcendència en la vivència religiosa actual. Knoblauch pren com a punt de partida la comparació entre el creixement del pentecostalisme i les noves formes d'espiritualitat i ens diu que, malgrat les diferències evidents entre tots dos moviments ${ }^{5}$, tenen en comú la importància crucial que atorguen a l'experiència subjectiva i individual de la vivència de la transcendència ${ }^{6}$. És la relació

4. Òbviament, avui dia es produeixen moltes altres transformacions que també seria pertinent destacar, com ara la importància de les comunitats transnacionals (Levitt, 2006), l'impacte de les noves tecnologies, la creació de models nous de comunitat, l'organització en forma de xarxa, etc. Recollir-los tots, però, supera amb escreix l'abast d'aquest article.

5. Així, el pentecostalisme s'ha estès especialment entre les classes populars del Tercer Món, mentre que les noves formes d'espiritualitat tenen èxit, principalment, entre la classe mitjana europea. El pes de la institució i el tipus de lideratges també són fonamentalment diferents en tots dos tipus de moviments.

6. Descobriment que he vist verificat, també, en les meves pròpies recerques empíriques entre tots dos moviments (Griera, 2002, 2013). 
directa, viscuda - i àdhuc corporificada - de l'experiència religiosa el que se situa al centre de la relació amb el transcendent. Ja no es tracta de ser-ne un espectador, sinó que hom n'ha de ser el protagonista i ha de poder "palpar, sentir, viure» la relació amb la transcendència. És, també, un procés pel qual l'emoció adquireix una centralitat especial en la construcció de la vivència religiosa: els fidels pentecostals que reben el do de la glossolàlia i que criden paraules estranyes, ploren, riuen o es desmaien i els practicants de les noves formes d'espiritualitat senten l'energia i l'experimenten en el propi cos a través de dispositius i tècniques diverses (Riis i Woodhead, 2010). La importància que adquireix l'experiència subjectiva d'allò transcendent no és banal, sinó que té conseqüències diverses en la manera de viure i d'organitzar la religió. És fonamental tenir en compte que això provoca una situació on és l'experiència -i la intensitat, la forma i les característiques d'aquesta- la que es converteix en font d'autentificació de l'experiència amb el transcendent. Així, el fidel pentecostal sap que ha rebut el bateig de l'Esperit Sant perquè ho ha pogut sentir. És l'experiència emocional vehiculada a través del cos la que li permet atribuir caràcter de veritat a la seva relació amb déu. Aquest fet té, òbviament, conseqüències per la manera com es concebrà l'autoritat ${ }^{7}$ i les figures de mediació. En aquest sentit, el líder religiós i espiritual deixa de ser l'autentificador de la fe per passar a convertir-se en un guia, en un orientador, en un monitor que ensenya el mètode. La veritat ja no és quelcom que el fidel busqui «fora», sinó que la veritat és, en certa manera, "dins»" ${ }^{8}$ i és necessari tenir dispositius i/o de tècniques que permetin accedir a aquesta «veritat». En certa manera, Knoblauch, vinculant-ho amb les aportacions de Troeltsch (1992: 146), ens diu:

[...] el carisma no està restringit només als virtuosos ni és regulat per les organitzacions religioses, sinó que esdevé generalitzat i subjectivitzat. És més, és l'experiència subjectiva de la transcendència —que esdevé potencialment a l'abast de tothom - la que defineix la creença i no pas el dogma.

No ens hi podem entretenir, però cal fer constar que aquesta transformació no és, en cap cas, exclusiva del pentecostalisme o dels nous tipus d'espiritualitat: és perceptible també en alguna de les pràctiques del moviment catòlic Comunió i Alliberament o El Camí Neocatecumenal, passant per alguns corrents de l'islam sufí o aleví o el creixement del hassidisme dins del món jueu, entre molts d'altres. També és necessari fer evident la connexió d'aquesta transformació amb canvis més grans que es produeixen a la societat en general (González Balletbó, 2010; Lacroix, 2005; Illouz, 2008).

D'altra banda, una segona característica crucial de transformació de l'escenari religiós en l'actualitat és, com hem mencionat, la importància que

7. Chaves (1994) fa un diagnòstic similar quan afirma que s'ha produït un canvi en la manera d'exercir l'autoritat religiosa. És a dir, avui l'autoritat religiosa no té la força d'antany i trobem certes formes individualitzades de creure que s'imposen cada dia més arreu.

8. Hem d'entendre que aquest «dins» comporta nombrosos matisos i subtilitats, segons el context religiós i espiritual en el qual s’utilitzi. 
adquireixen les religions com a vector per a la mobilització identitària. Vinculat a un context de postguerra freda, on el món bipolar ha donat lloc a un món multipolar $i$, en certa manera, orfe de grans identificacions collectives, la religió emergeix com a vehicle per a la generació i la mobilització d'identitats col-lectives. D'aquesta manera, la religió esdevé un recurs cultural (Beckford, 2003) a l'abast i disponible per definir els contorns d'una identitat i descriure «el conjunt de característiques que fan que una persona o una comunitat sigui ella mateixa» (DIEC, Identitat). Aplicat en un cas pràctic, és el que Oliver Roy (2004) explica en narrar la creixent identificació musulmana dels joves de la periferia francesa. El fet que estiguin en una posició marginal i que la identificació amb el país de recepció (França) en certa manera hagi fracassat, ha portat aquests joves a buscar altres mecanismes identitaris que els permetin descriure qui són $\mathrm{i}$, alhora, afrontar activament la frustració que els porta no ser reconeguts com a membres de ple dret de França. L'islam compleix aquesta funció $i$ els atribueix una identitat cultural que els permet diferenciar-se i donar sentit a la seva marginació. I és que, en certa manera, el fet que l'islam adquireixi més rellevància pública $\mathrm{i}$ aparegui com un nou vehicle mobilitzador a nivell públic pot provocar que persones que fins aleshores no havien atribuït rellevància a la seva religió d'origen li atorguin més pes en la seva identificació pública i en la seva autoidentificació. El context migratori pot afavorir, especialment, aquests processos. Així, el fet que ser musulmà aparegui com el recurs més a l'abast per sumar-se a una comunitat i el fet que la «musulmanitat» aparegui com el tret més visible per etiquetar l'estranger, dificulta que la identitat religiosa pugui ser viscuda de forma banal (Koenig, 2005). Ara bé, no és estrictament necessari trobar-se en una posició de marginació ni habitar a les periferies franceses perquè la religió funcioni com a recurs identitari i adquireixi més preeminència en l'autoidentificació individual. En aquest sentit, és important fer palès que malgrat que, sovint, en parlar d'identitat i de religió, hom ho associa, gairebé automàticament, a fonamentalisme, conservadorisme o integrisme, la religió esdevé un recurs identitari, tant per a aquells qui viuen la seva adhesió religiosa de forma militant com per a aquells qui hi tenen un vincle més dèbil (Martínez-Ariño, 2012a i 2012b). Així, la religió també s'utilitza com a recurs identitari per aquells qui l'adscripció religiosa resulta ser, gairebé, una categoria atributiva i justifiquen, així, una pràctica feble, però que, alhora, pren força en moments puntuals de la vida individual (mort, malaltia, celebracions) i de la social (defensa d'una memòria determinada, commemoració col-lectiva, etc.). És aquesta importància de la religió com a font d'identitat cultural —i de memòria — la que farà que hi hagi ciutadans que «' indignin davant els canvis de la religió, critiquin la secularització de les esglésies, protestin contra la construcció de les mesquites, encara que no posin els peus en una església tret que la campana soni per a ells» (Hervieu-Léger, 2002: 12). La importància de la religió com a font d'identitat individual i comunitària atribueix, també, unes funcions característiques a la institució religiosa. En aquest sentit, és imprescindible que es mantingui la institució i que adopti el rol de "guardiana» de la tradició. Per tal que la religió 
pugui funcionar com a vehicle identitari, és necessari que hi hagi una «minoria activa» que mantingui les institucions — amb les quals la majoria adopta una actitud de free-rider. És a dir, es tracta d'una religió que funciona «vicàriament", tal com posa de manifest Grace Davie (2006: 22), per a qui la religió vicària és aquella «que manté i porta a terme una minoria en nom de moltes altres persones, les quals (almenys, implícitament) no només estan al corrent d'allò que fa la minoria activa, sinó que clarament aproven el que està fent».

Els dos canvis que hem destacat: la preeminència de l'experiència subjectiva de la transcendència i el paper de les religions com a font d'identitat individual i col-lectiva són, com ja hem dit, canvis d'ordre diferent i que, a més, emergeixen per raons distintes. Tots dos, però, tenen en comú que afavoreixen — si bé de maneres molt diferents- l'efervescència religiosa en el món contemporani. I si cal destacar-los tots dos és perquè, sovint, en parlar de les transformacions de la religiositat en l'època actual, ho acostumem a fer o bé des de la perspectiva de la identitat i tots els discursos associats (Roy, 2003; Berger, 1999; Kepel, 1994), o bé des d'una vessant més fenomenològica, incidint en el canvi en les maneres de creure (Hervieu-Léger, 1999; Heelas i Woodhead, 2005, McGuire, 2008). Anomenar una qüestió i oblidar l'altra vol dir fixar-nos només en una part de l'escenari i és, alhora, confondre un escenari que ja ho és prou de per si ${ }^{9}$. És més, cadascun d'aquests dos fenòmens pot tenir, en determinats moments, efectes contraris, la qual cosa en dificulta l'anàlisi. En aquest sentit, per exemple, la importància que adquireix l'experiència subjectiva de la transcendència pot comportar una certa redefinició del rol de la institució religiosa i facilitar processos de desinstitucionalització i/o de desregulació institucional del fet de creure; posant en dubte, a més, les formes tradicionals d'autoritat en el marc d'aquestes institucions. En canvi, el creixement de la religió com a vehicle identitari atribueix més pes a la institució religiosa i la dota d'un paper essencial en tant que guardiana de la tradició i la memòria. És a dir, revesteix les institucions religioses d'una importància fonamental. En aquesta mateixa línia, mentre el primer fenomen emmarca l'experiència religiosa dins d'allò concebut com a «íntim» i pertanyent a l'àmbit privat o de la comunitat, l'experiència emocional vinculada a la creença s'experimenta, es viu i es transmet dins dels espais configurats dins les fronteres d'allò considerat íntim i personal. Alhora, però, la importància creixent de la religió com a mecanisme identitari qüestiona els llindars entre l'espai públic i el privat, com també el rol que se li havia assignat. Quan la religió esdevé font d'identitat, la seva influència no es limita a l'esfera privada, sinó que és, principalment, en l'àmbit públic on adquireix sentit. Habitualment, en fer referència a aquesta qüestió, hom acostuma a emfasitzar el cas de l'islam, tot i que no és quelcom exclusiu d'aquesta creença. Ens referim, també, per exemple, a l'emergència d'una organització com ara Majoria Moral als EUA o a la importància creixent de determinats moviments catòlics (Ferrari, 2008)

9. Per a una anàlisi més aprofundida sobre aquestes dues qüestions, vegeu Griera (2009, 2012). 
en la repolitització de la vida privada en clau religiosa i, alhora, l'aparició de discursos religiosos en el debat polític a l'esfera pública. I és que la religió, com diuen James Beckford i John Walliss (2006), és utilitzada com a «recurs cultural» per determinats grups socials a l'hora de construir la seva identitat i de reivindicar-la a l'esfera pública. Hi ha determinats autors que, davant d'aquesta situació, argumenten que, per tant, el debat no és religiós, sinó polític i/o ideològic. Tanmateix, però, en certa manera, i si tenim en compte que la religió també té una dimensió com a identitat cultural, aquest tipus d'argumentacions esdevenen estèrils. ¿Quina rellevància té que l'investigador s'entossudeixi a dir que això no són expressions veritablement religioses, sinó fruit del descontentament social o del creixement de la incertesa, si els seus protagonistes utilitzen la variable religiosa com a vincle d'enllaç i la reivindiquen com a identitat principal? El més interessant de comprendre sociològicament no és si el caràcter religiós d'aquestes reivindicacions és vertaderament religiós, sinó, més aviat, entendre per què és justament la religió la que compleix aquestes funcions avui.

\section{Apunts finals}

En les darreres dècades, el paradigma de la secularització ha perdut credibilitat i són nombrosos els esdeveniments —alguns dels quals hem mencionat en aquest article - que han desafiat les categories a partir de les quals s'analitzava $\mathrm{i}$ es concebia la religiositat des de les ciències socials. Avui dia, existeixen explicacions plausibles - com també hem esmentat- que ens permeten comprendre les raons darrere el diagnòstic fallit de la secularització. Alhora, emergeixen cada vegada amb més força aquells qui reclamen una mirada sobre el fet religiós realitzada amb la voluntat de comprendre com es reconfiguren les maneres de creure en el context diari i quotidià, com es defineixen les identitats $\mathrm{i}$ les pertinences i com es construeixen les comunitats i les organitzacions religioses en la societat actual. Aproximacions fetes a partir de treballs empírics i des d'una perspectiva que es fixa més en els canvis de caràcter qualitatiu que no pas quantitatiu (Chaves, 1994; Davie, 2004).

Dit això, i a manera de reclam final, cal aclarir que esdevé imprescindible tenir en compte que la crítica a la teoria de la secularització, si bé és necessària i pertinent, no pot substituir-se per una mirada ingènua que, dels processos d'efervescència religiosa creixent, en faci veredictes definitius i amb caràcter universal. Alhora, també, i per no caure en lectures simplistes, és important tenir en compte que la teoria de la secularització no fou, només, una teoria acadèmica, sinó que també va tenir un paper clau a imbricar un projecte polític vinculat a la democràcia occidental, els principis del qual, encara avui —i malgrat els debats existents_-, impregnen el funcionament de les societats europees. És a dir, reconèixer l'error de predicció de la teoria de la secularització i explicar-ne les causes no pot portar-nos, ingènuament, a obviar-ne les conseqüències polítiques, socials i culturals que ha tingut. I és que, com diu el teorema de Thomas: «El que ha estat definit com a real, té conseqüències reals». 


\section{Referències bibliogràfiques}

Anderson, B. (1993). Imagined communities: Reflections on the origin and spread of nationalism. Londres/Nova York: Verso.

Anderson, A. (2004). An Introduction to Pentecostalism: Global Charismatic Christianity [en línia]. Cambridge: Cambridge University Press. $<$ http://www.arsdisputandi.org/publish/articles/000173/article.pdf $>$.

AsAD, T. (1993). Genealogies of religion: Discipline and reasons of power in Christianity and Islam. Baltimore: Johns Hopkins University Press.

- (2003). Formations of the Secular: Christianity, Islam, Modernity. Standford: Standford University Press.

BAder, V. (2007). Secularism or Democracy?: Associational Governance of Religious Diversity. Amsterdam: Amsterdam University Press. <http://dx.doi.org/10.5117/9789053569993>

Barret, D.; Kurian, G. i Johnson, T. (2001). World Christian Encyclopedia: A Comparative Survey of Churches and Religions in the Modern World. Oxford: Oxford University Press.

Bastian, J. P. (1997). La mutación religiosa de América Latina: Para una sociología del cambio social en la modernidad periférica. Mèxic: Fondo de Cultura Económica.

Beckford, J. (2003). Social Theory and Religion. Cambridge: Cambridge University Press.

Beckford, J. i Walliss, J. (2006). Theorising Religion: Classical and Contemporary Debates. Londres: Ashgate Publishing, Ltd. <http://dx.doi.org/10.1017/CBO9780511520754>

Berger, P. (1999). "The desecularization of the World: A Global Overview». A: Berger, P. (ed.). The Desecularization of the World: Resurgent Religion and World Politics. Washington, DC: Ethics and Public Policy Center i William B. Eerdmans Publishing Company.

- (2005). «Pluralismo global y religión». Revista de Estudios Públicos, 98.

Berger, P.; Davie, G. i Fokas, E. (2008). Religious America, Secular Europe?: $A$ Theme and Variations. Londres: Ashgate Pub. Co.

Borowik, I. (2002). «Between Orthodoxy and Eclecticism: on the Religious Transformations of Russia, Belarus and Ukraine». Social Compass, 49 (4), 497. <http://dx.doi.org/10.1177/0037768602049004002>

BRUCE, S. (1993). «Religion and rational choice: a critique of economic explanations of religious behavior». Sociology of Religion, 54 (2), 193-205. $<$ http://dx.doi.org/10.2307/3712139>

Cantón Delgado, M. (1998). Bautizados en fuego: Protestantes, discursos de conversión y política en Guatemala (1989-1993). La Antigua (Guatemala): Centro de Investigaciones Regionales de Mesoamérica (CIRMA) / South Woodstock, Vermont (Estados Unidos): Plumsock Mesoamerican Studies (PMS).

Casanova, J. (1994). Public religions in the modern world. Chicago: The University of Chicago Press, 320 . 
- (2007). «Immigration and the New Religious Pluralism: A European Union / United States ComParíson». A: Banchoff, T. (ed.). Democracy and the new religious pluralism. Nova York: Oxford University Press.

Chaves, M. (1994). «Secularization as declining religious authority». Social Forces, 72 (3),749-774.

$<$ http://dx.doi.org/10.2307/2579779>

$<\mathrm{http}: / /$ dx.doi.org/10.1093/sf/72.3.749>

Corten, A. i Marshall-Fratani, R. (2001). Between Babel and Pentecost: Transnational Pentecostalism in Africa and Latin America. Bloomington, IN: Indiana University Press.

Davie, G. (2002). Europe: The Exceptional Case. Parameters of Faith in the Modern World. Londres: Darton, Longman \& Todd.

- (2004). «New Approaches in the Sociology of Religion: A Western Perspective». Social Compass, 51 (1), 73.

- (2006). «Vicarious Religion: A Methodological Challenge». A: Ammerman, N. T. (ed.). Everyday Religion: Observing Modern Religious Lives. Nova York: Oxford University Press.

- (2006b). «Religion in Europe in the 21st Century: The Factors to Take into Account». Arch. Europ. sociol., XLVII, 271-296.

Díaz-SALAZAR, R. (2008). «La cohesión social y las formas públicas de religión en las sociedades contemporáneas». A: Bericat (ed.). Presencia de la religión y de la religiosidad en una sociedad avanzada. Sevilla: Centro de Estudios Andaluces.

Eisenstadt, S. (2002). Multiple Modernities. Boston/Leiden: Brill.

EstradÉ, A. (2003). «La religió i els joves: Velles preguntes per a noves realitats». A: Joves i valors: Els joves catalans en l'Enquesta Europea de Valors. Barcelona: Generalitat de Catalunya. Col-lecció Estudis.

Estruch, J. (1981). «El mite de la secularització». Enrahonar: Quaderns de filosofia [en línia], 2. <http://ddd.uab.cat/pub/enrahonar/0211402Xn2p39.txt>.

Fedele, A. (2009). «From Christian religion to feminist spirituality: Mary Magdalene pilgrimages to La Sainte-Baume, France». Culture and Religion, 10 (3), 243-261.

FERRARI, S. (2008). «State regulation of religion in the European democracies: The decline of the old pattern». A: Motzkin, G. i Fischer, Y. (eds.). Religion and Democracy in Contemporary Europe. Londres: Alliance Publishing Trust.

García-Romeral, G. (2013). «Comunitats islàmiques de Catalunya. Desenvolupament comunitari, moviments i organitzacions islàmiques». Diversia, 3, 93-131.

GonzÁlez BAlletbó, I. (2010). Els tres esperits de la segona modernitat: Un marc conceptual per a l'anàlisi de les desigualtats socials contemporànies. Bellaterra: Universitat Autònoma de Barcelona.

Griera, M. (2009). De la religió a les religions: Polítiques públiques i minories religioses a Catalunya. Tesi doctoral. Barcelona: Departament de Sociologia. Universitat Autònoma de Barcelona. 
- (2012) «Public Policies, Interfaith Associations and Religious Minorities: A New Policy Paradigm? Evidence from the Case of Barcelona». Social Compass, 59, 570-587.

- (2013). «New Christian geographies: Pentecostalism and immigration in Barcelona». A: Mapril, J. i Blanes, R. (eds.). Sites and Politics of Religious Diversity in Southern Europe. Leiden/Boston: Brill.

Griera, M. i Urgell, F. (2002). Consumiendo religión: Nuevas formas de espiritualidad entre la población juvenil. Barcelona: Fundació 'la Caixa'.

Habermas, J. (2006). «Religion in the public sphere». European Journal of Philosophy, 14 (1), 1-25.

Heelas, P.; Woodhead, L.; Seel, B.; Szerszynski, B. i Tusting, K. (2005). The spiritual revolution: Why religion is giving way to spirituality [en línia]. Blackwell Pub. <http://www.lavoisier.fr/livre/notice.asp?id= RKOWARA R6A6OWJ>.

Hervieu-LÉger, D. (1993). La religion pour mémoire. París: Cerf.

- (1999). La religion en mouvement: Le pèlerin et le converti. París: Flammarion.

- (2002). «La transmission des identités religieuses». Sciences Humaines: Hors Série, 36, 56-59.

Houtman, D. i Aupers, S. (2007). "The Spiritual Turn and the Decline of Tradition: The Spread of Post-Christian Spirituality in 14 Western Countries, 1981-2000». Journal for the Scientific Study of Religion, 46 (3), 305-320.

Illouz, E. (2008). Saving the modern soul: Therapy, emotions, and the culture of self-help. California: University of California Press.

KePEL, G. (1994). The revenge of God: The resurgence of Islam, Christianity, and Judaism in the modern world. Pensilvania: Pennsylvania State University Press.

Knoblauch, H. (2008). «Spirituality and popular religion in Europe». Social Compass, 55 (2), 140-153.

Koenig, M. (2005). "Incorporating Muslim migrants in western nation states-a comParíson of the United Kingdom, France, and Germany». Journal of International Migration and Integration, 6 (2), 219-234.

Kunn, T. S. (1962). The structure of scientific revolutions. Chicago: University of Chicago Press.

Lacroix, M. (2005). El culte a l'emoció: Atrapats en un món d'emocions sense sentiments. Barcelona: La Campana.

Laurence, J. (2006). «Managing transnational Islam: Muslims and the state in Western Europe». A: Parsons, C. i Smeeding, T. (eds.). Immigration and the Transformation of Europe. Cambridge: Cambridge University Press.

LeVITT, P. (2006). "God needs no passport: How immigrants are changing american religious life». Harvard Divinity Bulletin, Fall 2006, 45-57.

Martin, D. (1990). Tongues of Fire: The Explosion of Protestantism in Latin America. Oxford: Basil Blackwell.

- (2002). Pentecostalism: The world their Parish. Oxford: Blackwell Oxford.

MARTíneZ-ARIÑo, J. (2012a). Las comunidades judias contemporáneas de Cataluña: Un estudio sociológico a través de los procesos de construcción y transmi- 
sión identitaria. Tesi doctoral. Bellaterra: Departament de Sociologia. Universitat Autònoma de Barcelona.

- (2012b). «Identidades y vivencias judías en la Cataluña contemporánea: una realidad diversa y cambiante». Quaderns-e de l'Institut Català d'Antropologia, 1 (2), 73-85.

McGuire, M. B. (2008). Lived religion: Faith and practice in everyday life. Nova York: Oxford University Press.

Méndez, C. (2005). Por el camino de la participación: Una aproximación contrastada a los procesos de integración social y política de los gitanos y las gitanas en Catalunya. Tesi doctoral inèdita. Barcelona: Departament d'Antropologia. Universitat Autònoma de Barcelona.

Muntanyola, D. (2013). "A Contemporary Cognitive Account of Expertise: Why Rational Choice Theory is (often) a Fiction». Theory \& Psychology.

RiIs, O. i Woodhead, L. (2010). A sociology of religious emotion. Oxford: Oxford University Press.

Roy, O. (2004). Globalised Islam: The search for a new ummah. Londres: C. Hurst i Co. Publishers.

SÁez, A. (1997). El llenguatge cristià en la cultura de masses. Barcelona: Cruïlla.

Stark, R. (1999). «Secularization, R.I.P. (Rest in Pace)». Sociology of Religion, 60 (3), 249-273.

Stark, R. i Finke, R. (2000). Acts of Faith. Berkeley, CA: University of California Press.

Stark, R. i Iannaccone, L. (1994). "A supply-side reinterpretation of the "secularization" of Europe». Journal for the Scientific Study of Religion, 33 (3), 230-252.

Stoll, D. (1990). ¿América Latina se vuelve protestante? Cayambe: Abya-Yala Ed.

Thomas, S. M. (2000). «Taking Religious and Cultural Pluralism Seriously: The Global Resurgence of Religion and the Transformation of International Society». Millennium: Journal of International Studies, 29 (3).

- (2005). Global Resurgence of Religion and the Transformation of International Relations. Nova York: Palgrave MacMillan.

Troeltsch, E. (1992). The social teachings of Christian Churches. Louisville: Westminster/John Knox.

Tschannen, O. (1997). «The Secularization Paradigm: A Systemization». Journal for the Scientific Study of Religion, 30 (4).

Turner, B. S. (2007). «Managing religions: State responses to religious diversity». Contemporary Islam, 1 (2), 123-137.

Vasquez, M. A. (1999). «Pentecostalism, collective identity, and transnationalism among Salvadorans and Peruvians in the US». Journal of the American Academy of Religion, 67 (3), 617-636.

YAMANE, D. (1997). «Secularization on Trial: In defense of a Nonsecularization paradigm». Journal for the Scientific Study of Religion, 36 (1), 109-122. 
Mar Griera és doctora en Sociologia per la Universitat Autònoma de Barcelona (2009). Actualment, és professora lectora del Departament de Sociologia de la Universitat Autònoma de Barcelona i investigadora de l'equip de recerca ISOR i del Centre de Sociologia de les Religions i d'Ettica Social de la Universitat Marc Bloch (Estrasburg). Ha estat investigadora convidada a l'Institut de Cultura, Religió i Afers Mundials de la Universitat de Boston, a l'Institut de Migració i Estudis Ėtnics (IMES) de la Universitat d'Amsterdam i al Departament de Sociologia de la Universitat d'Exeter, entre d'altres. L'any 2003, fou guanyadora del XV Premi de Recerca en Ciències Socials «Rogeli Duocastella» (amb Ferran Urgell), per una recerca sobre noves formes de religiositat entre els joves. Al llarg de la seva trajectòria com a investigadora, ha participat $\mathrm{i}$ ha coordinat diversos projectes de recerca sobre temes vinculats a la sociologia de la cultura $\mathrm{i}$ la religió.

Mar Griera works as a lecturer at the department of Sociology, Universitat Autònoma de Barcelona. She was awarded a PhD on Sociology from the Universitat Autònoma de Barcelona (2009) for her work on public policies and religious minorities. She is research associate at the ISOR (UAB) and at the Centre de Sociologie des Religions et d'Éthique Sociale de la Université Marc Bloch (Strasbourg, France). She has been visitor fellow at the Institute on Culture, Religion and World Affairs (Boston University) and at the Institute for Migration and Ethnic Studies (Amsterdam University) among others. From 2000 onwards she has been researching on sociology of culture and religion and coordinating several projects in this area. 